\title{
ALTERED ENDOTHELIUM-DERIVED HYPERPOLARIZING FACTOR-MEDIATED ENDOTHELIAL FUNCTION IN CORONARY MICROARTERIES BY ST THOMAS' HOSPITAL SOLUTION
}

Zhi-Dong Ge, MD

Guo-Wei He, MD, PhD
Objectives: We examined the effect of St Thomas' Hospital solution on endothelium-derived hyperpolarizing factor-mediated function in the porcine coronary microarteries with emphasis on the effect of temperature and washout time. Methods: Microartery rings (diameter, 200-450 $\mu \mathrm{m})$ were studied in myograph. The arteries were incubated in $\mathrm{St}$ Thomas' Hospital or Krebs solution (control) at $4^{\circ} \mathrm{C}$ for 4 hours followed by 45 minutes (group Ia) or 90 minutes washout (group Ib) or at $22^{\circ} \mathrm{C}$ for 1 hour followed by 45 minutes (group IIa) or 90 minutes washout (group IIb) and precontracted with $-8.5 \log M \mathrm{U}_{46619^{\circ}}$ The endothelium-derived hyperpolarizing factor-mediated relaxation to bradykinin was studied when endothelium-derived nitric oxide and prostaglandin $I_{2}$ were inhibited with the presence of $7 \mu \mathrm{mol} / \mathrm{L}$ indomethacin and $300 \mu \mathrm{mol} / \mathrm{L} \mathrm{N}^{\mathrm{G}}$-nitro-L-arginine. Results: After exposure to St Thomas' Hospital solution, the maximal endothelium-derived hyperpolarizing factor-mediated relaxation (percentage of the precontraction) was significantly reduced at either temperature after washout for 45 minutes (group Ia, $42.7 \% \pm 3.5 \%$ vs $69.0 \% \pm 5.3 \%$; $n=9 ; P=$ .000 ; and group IIa, $12.3 \% \pm 1.6 \%$ vs $56.1 \% \pm 4.4 \% ; n=8 ; P=.000$ ) but fully recovered after washout for 90 minutes. The $U_{46619}$-induced contraction force was also significantly reduced after washout for $\mathbf{4 5}$ minutes $(P<.001)$ but fully recovered at 90 minutes. Conclusions: Under profound and moderate hypothermia, St Thomas' Hospital solution impairs endothelium-derived hyperpolarizing factor-mediated relaxation and smooth muscle contraction in the coronary microarteries. These effects exist during the reperfusion period for at least 45 minutes after exposure to St Thomas' Hospital solution and may account for the possible myocardial dysfunction during reperfusion. ( $J$ Thorac Cardiovasc Surg 1999;118:173-80)
S t Thomas' Hospital solution (STS) has been in widespread clinical use to arrest the heart for precise intracardiac reconstruction or coronary grafting in

From the Cardiovascular Research Laboratory, Grantham Hospital, and Division of Cardiothoracic Surgery, Department of Surgery, University of Hong Kong, Aberdeen, Hong Kong.

Supported in part by Hong Kong Research Grants Council grant (HKU7280/97M), the University of Hong Kong Committee of Research and Conference Grants (337/048/0018, 335/048/0079), and the University of Hong Kong Grants (014/048/9602, 344/048/0001).

Received for publication Aug 4, 1998; revisions requested Oct 6, 1998; revisions received March 2, 1999; accepted for publication March 16, 1999.

Address for reprints: Professor Guo-Wei He, MD, PhD, Chair of Cardiothoracic Surgery, University of Hong Kong, Grantham Hospital, 125 Wong Chuk Hang Rd, Aberdeen, Hong Kong.

Copyright (C) 1999 by Mosby, Inc.

$0022-5223 / 99 \$ 8.00+0 \quad \mathbf{1 2 / 1 / 9 8 5 8 3}$ combination with hypothermia or normothermia. In addition, it has also been used to preserve the donor heart under hypothermia for transplantation. During the cardioplegic arrest, coronary vascular endothelium is in direct contact with this solution. Therefore an important issue is whether STS affects endothelial cells and, subsequently, causes the change of coronary vascular reactivity. Several previous studies have focused on the preservation of myocardial function in evaluating the efficacy of this cardioplegic solution. ${ }^{1,2}$ In addition, attention has been paid to the effect of this solution on coronary endothelial function. ${ }^{3,4}$

Vascular endothelium plays a key control role in the regulation of vascular tone through releasing diverse vasoactive substances. Among those, endotheliumderived relaxing factors (EDRFs) are responsible for endothelium-dependent relaxation. ${ }^{5}$ The major compo- 
nents of EDRFs have been shown to be endotheliumderived nitric oxide (EDNO), epoprostenol (prostacyclin $\left[\mathrm{PGI}_{2}\right]$ ), and endothelium-derived hyperpolarizing factor (EDHF). ${ }^{6,7}$ It is generally considered that EDHF plays a significant role in the regulation of microvasculature and thus of blood flow distribution. ${ }^{8}$ Because the coronary microvascular system plays the key role in the regulation of myocardial perfusion, the investigation on the effect of STS on EDHF-mediated function in the coronary microvascular system is particularly important during cardioplegic arrest. ${ }^{9}$ However, this has not been studied.

Potassium $\left(\mathrm{K}^{+}\right)$at high concentrations (hyperkalemia) is a known vascular irritant. ${ }^{10,11}$ Hyperkalemia has been shown to damage endotheliumdependent relaxation. ${ }^{4,12,13}$ In those studies, the $\mathrm{K}^{+}$ concentrations ranged from 16 to $125 \mathrm{mmol} / \mathrm{L}$. Recently, we have performed a series of experiments that show that hyperkalemia impairs EDHF-mediated endothelial function in large conduit coronary arteries. $^{7,14-16}$ However, the components of STS are complex; the effect of other components in STS, such as magnesium and procaine, and the effect of STS as a whole remain unknown. Further, the previous studies regarding the effect of hyperkalemia on the EDHFmediated function were performed in large coronary arteries and whether this is true in the more important resistant arteries (microarteries) is unknown.

In addition, 2 other factors (ie, temperature and washout time) may also affect the possible effect of STS on the endothelial function.

The present study was therefore designed to examine the effect of STS on EDHF-mediated endothelial function when the EDNO and $\mathrm{PGI}_{2}$ were inhibited by specific inhibitors in porcine coronary microarteries, with emphasis on the effect of temperature and washout time.

\section{Materials and methods}

Arterial preparation and mounting. Fresh porcine hearts collected from a local slaughterhouse were placed in a container filled with cold Krebs solution and immediately transferred to the laboratory. The transportation time varied from 1 to 2 hours. On receipt of the heart, intramyocardial coronary arteries (usually the tertiary branches of the left anterior descending artery) in diameter of 200 to $450 \mu \mathrm{m}$ at pressure of $100 \mathrm{~mm} \mathrm{Hg}$ were carefully dissected out, with care taken to protect the endothelium. The vessel was cleaned of fat and connective tissue and cut into cylindric rings of $2 \mathrm{~mm}$ long under a microscope. The ring was guided a suitable length through its lumen by a pair of stainless steel wires $(40 \mu \mathrm{m}$ in diameter). One wire was fixed tightly on a jaw in a 2-channel myograph (model 500A; J P Trading, Aarhus, Denmark), ${ }^{17}$ and another wire was passed lightly through the vascular lumen and anchored another jaw of the same chamber. These 2 wires were attached to a force transducer or to a micrometer, respectively. An adjustable micrometer can pull the jaws apart and stretch the artery between the 2 parallel wires. A calibrated force transducer was used to measure the force, with the output shown on a computer screen and printed in a printer. Data were digitized and stored in the computer.

The Krebs solution had the following composition: $\mathrm{Na}^{+}$, $144 \mathrm{mmol} / \mathrm{L} ; \mathrm{K}^{+}, 5.9 \mathrm{mmol} / \mathrm{L} ; \mathrm{Ca}^{2+}, 2.5 \mathrm{mmol} / \mathrm{L} ; \mathrm{Mg}^{2+}, 1.2$ $\mathrm{mmol} / \mathrm{L} ; \mathrm{Cl}^{-}, 128.7 \mathrm{mmol} / \mathrm{L} ; \mathrm{HCO}_{3}^{-}, 25 \mathrm{mmol} / \mathrm{L} ; \mathrm{SO}_{4}{ }^{2-}, 1.2$ $\mathrm{mmol} / \mathrm{L} ; \mathrm{H}_{2} \mathrm{PO}_{4}^{-}, 1.2 \mathrm{mmol} / \mathrm{L}$; and glucose, $11.0 \mathrm{mmol} / \mathrm{L}$. During normalization or relaxation studies, the solution was aerated with a gas mixture of $95 \%$ oxygen and $5 \%$ carbon dioxide at $37^{\circ} \mathrm{C}$.

Two organ chamber arrangements in the same myograph were run concurrently.

Normalization. The vessels were equilibrated for $45 \mathrm{~min}$ utes. The arterial rings were progressively stretched until the passive transmural pressure reached $100 \mathrm{~mm} \mathrm{Hg}$, and then the pressure was immediately released. The computerized program determines the length-tension exponential curve for each ring and gives the internal circumference and diameter at a pressure of $100 \mathrm{~mm} \mathrm{Hg} \cdot{ }^{17,18}$ The internal circumference was then set to the value, estimated to be equivalent to $90 \%$ of the circumference at a passive transmural pressure of 100 $\mathrm{mm} \mathrm{Hg}{ }^{17}$ Only arterial rings in internal diameter of 200 to $450 \mu \mathrm{m}$ at the pressure of $100 \mathrm{~mm} \mathrm{Hg}$ were used in the present study. The experiment was performed at the internal diameter set up at $90 \%$ of the diameter (D0.9) under a pressure of $100 \mathrm{~mm} \mathrm{Hg}$ that is determined by the computer program. ${ }^{17,18}$ The transluminal pressure, read from the computer recording, at this diameter (D0.9) was between 55 and $70 \mathrm{~mm}$ $\mathrm{Hg}$ in our experiment. The whole experiment was then performed under this passive pressure (tension) on the vessel. The isometric force at this setting is the "passive" or "resting" force in the absence of constrictor tone. This method allows one to set the vessel in vitro at a physiologic pressure and has been shown to allow maximum tension development. In the myograph (model 500A), the normalization procedure was performed automatically. The diameter of the vessel at 100 $\mathrm{mm} \mathrm{Hg}$ was determined by the length-tension curve during the normalization procedure.

\section{Protocol}

Precontraction. The vessel was contracted with thromboxane $\mathrm{A}_{2}$ mimetic $\mathrm{U}_{46619}(-8.5 \log \mathrm{M})$. This dose was chosen because, in our experiments, the median effective concentration $\mathrm{EC}_{50}$ for $\mathrm{U}_{46619}$-induced contraction was $-8.78 \pm 0.14$ $\log M(n=9$ taken from 9 pig hearts), calculated from the concentration-response curves in porcine coronary microarteries. $\mathrm{U}_{46619}$ at $-8.5 \log \mathrm{M}$ caused a stable submaximal contraction of all rings.

EDHF-mediated (indomethacin and L-NNA-resistant) relaxation. With the presence of the specific inhibitor for cyclooxygenase indomethacin $(7 \mu \mathrm{m})$ and the EDNO synthase inhibitor $\mathrm{N}^{\mathrm{G}}$-nitro-L-arginine (L-NNA, $300 \mu \mathrm{mol} / \mathrm{L}$ ), concentration-relaxation curves to bradykinin ( -10 to -5.5 $\log \mathrm{M}$ ) were established when the $\mathrm{U}_{46619}$-induced contraction 
reached a plateau. This relaxation is considered to be related to the EDHF function because EDNO and $\mathrm{PGI}_{2}$ are blocked by indomethacin and L-NNA. The following protocol was used.

EXPERIMENTAL GROUP I: PROFOUND HYPOTHERMIA $\left(4^{\circ} \mathrm{C}\right)$ GROUP IA. The washout time was 45 minutes. In cold Krebs solution, 1 coronary arterial segment was cut into 2 pieces, each $2 \mathrm{~mm}$ long. Two chambers of the duel-chamber myograph was filled with either STS or Krebs solution (as the control) at $4^{\circ} \mathrm{C}$, respectively. Two rings were separately mounted in the 2 chambers, and the myograph was then placed in a refrigerator at $4^{\circ} \mathrm{C}$ for 4 hours. After storage for 4 hours, both rings were repeatedly washed with Krebs solution of $37.0^{\circ} \pm 0.1^{\circ} \mathrm{C}$ that had been aerated with $95 \%$ oxygen and $5 \%$ carbon dioxide gas. The normalization procedure was then performed, and $7 \mu \mathrm{mol} / \mathrm{L}$ indomethacin and $300 \mu \mathrm{mol} / \mathrm{L}$ L-NNA were added to the chambers. Twenty minutes later, the rings were precontracted with $\mathrm{U}_{46619}(-8.5 \log \mathrm{M})$. Cumulative concentration-response curves to bradykinin were then established. The washout time (the time between the washout of the cold STS or Krebs solution with warm Krebs solution and the start of the concentration-relaxation curve to bradykinin) was controlled at 45 minutes.

The composition of STS is $\mathrm{Na}^{+}, 138 \mathrm{mmol} / \mathrm{L} ; \mathrm{K}^{+}, 20$ $\mathrm{mmol} / \mathrm{L} ; \mathrm{Ca}^{2+}, 2.7 \mathrm{mmol} / \mathrm{L} ; \mathrm{Mg}^{2+}, 16 \mathrm{mmol} / \mathrm{L} ; \mathrm{Cl}^{-}, 157$ $\mathrm{mmol} / \mathrm{L} ; \mathrm{HCO}_{3}^{-}, 8 \mathrm{mmol} / \mathrm{L}$; lactate, $28 \mathrm{mmol} / \mathrm{L}$; and procaine, $1 \mathrm{mmol} / \mathrm{L}$. The osmolarity is 370 .

GROUP IB. The washout time was 90 minutes. In this group of experiments, 2 arterial rings ( $2 \mathrm{~mm}$ long) obtained from the same coronary arterial segment were immersed in either STS or Krebs solution (as the control) at $4{ }^{\circ} \mathrm{C}$ (in a refrigerator) for 4 hours. The rings were then taken from the refrigerator, repeatedly washed with Krebs solution of $37^{\circ} \pm 0.1^{\circ} \mathrm{C}$, and mounted on the dual-chamber myograph. After equilibration for 20 minutes, the arterial rings were normalized. Indomethacin $(7 \mu \mathrm{mol} / \mathrm{L})$ and $\mathrm{L}-\mathrm{NNA}(300 \mu \mathrm{mol} / \mathrm{L})$ were added into the chambers. Twenty minutes later, the rings were contracted with $\mathrm{U}_{46619}(-8.5 \log \mathrm{M})$. Cumulative concentration-response curves to bradykinin were then established. The washout time was controlled at 90 minutes.

EXPERIMENTAL GROUP II: MODERATE HYPOTHERMIA $\left(22^{\circ} \mathrm{C}\right)$. The arteries were incubated in either STS or Kreb's solution at room temperature $\left(22^{\circ} \mathrm{C}\right)$. The exposure time to either STS or Krebs solution (as the control) was 1 hour. Similar to that mentioned earlier, the washout time was either 45 (group IIa) or 90 minutes (group IIb).

In all experiments, only 1 concentration-relaxation curve was obtained from each coronary ring. A mean concentration-relaxation curve was established from 7 to 9 rings in each group of experiments. During the experiments, the Krebs solution in the myograph chamber was continuously bubbled with a gas mixture of $95 \%$ oxygen and $5 \%$ carbon dioxide.

Data analysis. Mean maximal relaxation for each group was calculated from the maximal relaxation of different rings induced by bradykinin. The effective concentration of the relaxation agent that caused $50 \%$ of maximal relaxation was defined as $\mathrm{EC}_{50}$. The $\mathrm{EC}_{50}$ was determined from each concentration-relaxation curve by a logistic, curve-fitting equation:

$$
\mathrm{E}=\mathrm{MA}^{\mathrm{P}} /\left(\mathrm{A}^{\mathrm{P}}+\mathrm{K}^{\mathrm{P}}\right)
$$

where $\mathrm{E}$ is response, $\mathrm{M}$ is maximal relaxation, $\mathrm{A}$ is concentration, $\mathrm{K}$ is $\mathrm{EC}_{50}$ concentration, and $\mathrm{P}$ is the slope parameter. ${ }^{18}$ From this fitted equation, the mean $\mathrm{EC}_{50}$ value \pm the SEM was calculated for each group.

Statistical analysis. All statistical analysis was performed with SPSS software (SPSS, Inc, Chicago, Ill). The significance of the difference between mean values was calculated by the paired Student $t$ test. Results are expressed as mean \pm SEM for observations of "n," where "n" equals the number of coronary arterial rings.

Drugs. Chemicals used and their sources were as follows: bradykinin, L-NNA, and indomethacin (Sigma Chemical Co, St Louis, Mo); $\mathrm{U}_{46619}$ (Cayman Chemical, Ann Arbor, Mich). L-NNA (dissolved in distilled water) and indomethacin (dissolved in ethanol) were stored at $4^{\circ} \mathrm{C}$. The solution of $\mathrm{U}_{46619}$ was held frozen until required. The STS was purchased from David Bull Laboratories, Mulgrave, Victoria, Australia.

\section{Results}

Resting force. There was no significant difference between the arteries exposed to STS and the control with regard to the resting force after the various exposure time at either temperature $(P>.05)$. Table I gives the details of the resting force in these microarteries.

Indomethacin $(7 \mu \mathrm{mol} / \mathrm{L})$ plus L-NNA $(300 \mu \mathrm{mol} / \mathrm{L})$ induced a slow and slight increase in the basal tone of coronary rings in all groups. It was $0.1 \pm 0.1 \mathrm{mN}(1 \mathrm{~g}$ $=9.8 \mathrm{mN})$ vs $0.0 \pm 0.1 \mathrm{mN}$ in the control in group Ia $(\mathrm{n}$ $=9 ; 95 \%$ confidence interval $[\mathrm{CI}],-0.5$ to $0.3 \mathrm{mN} ; P=$ .7), $0.5 \pm 0.4 \mathrm{mN}$ versus $0.6 \pm 0.2 \mathrm{mN}$ in the control in group $\mathrm{Ib}(\mathrm{n}=7 ; 95 \% \mathrm{CI},-0.6$ to $0.8 \mathrm{mN} ; P=.7), 0.6 \pm$ $0.2 \mathrm{mN}$ versus $0.8 \pm 0.3 \mathrm{mN}$ in the control in group IIa (n $=8,95 \%$ CI: -0.3 to $0.8 \mathrm{mN}, P=.3$ ), and $0.5 \pm 0.2$ $\mathrm{mN}$ versus $0.4 \pm 0.2 \mathrm{mN}$ in the control in group $\mathrm{IIb}(\mathrm{n}=$ 8 ; $95 \% \mathrm{CI},-0.4$ to $0.3 \mathrm{mN} ; P=.8)$.

$\mathrm{U}_{46619}$-induced contraction force. In all coronary arterial rings, $\mathrm{U}_{46619}(-8.5 \log \mathrm{M})$ induced a stable and rapidly developing tension. This contraction force was reduced by exposure to STS when measured at washout for 45 minutes (group Ia, $9.5 \pm 0.9 \mathrm{mN}$ vs 14.6 $\pm 0.7 \mathrm{mN} ; \mathrm{n}=8 ; 95 \% \mathrm{CI}, 3.1$ to $7.2 \mathrm{mN} ; P=.000$; group IIa, $8.9 \pm 0.1 \mathrm{mN}$ vs $13.0 \pm 0.1 \mathrm{mN} ; \mathrm{n}=8 ; 95 \%$ CI, 2.4 to $5.9 \mathrm{mN} ; P=.001)$. However, when washout period was prolonged to 90 minutes, the contraction to $\mathrm{U}_{46619}$ had no difference compared with the control (group Ib, $14.1 \pm 1.7 \mathrm{mN}$ vs $14.6 \pm 1.5 \mathrm{mN} ; \mathrm{n}=7 ; 95 \%$ $\mathrm{CI},-2.8$ to $3.8 \mathrm{mN} ; P=.7$; and group IIb, $13.3 \pm 0.1$ $\mathrm{mN}$ vs $13.5 \pm 0.1 \mathrm{mN} ; \mathrm{n}=9 ; 95 \% \mathrm{CI},-2.2$ to $2.5 \mathrm{mN}$; $P=0.9$ ). These results demonstrate that the smooth 


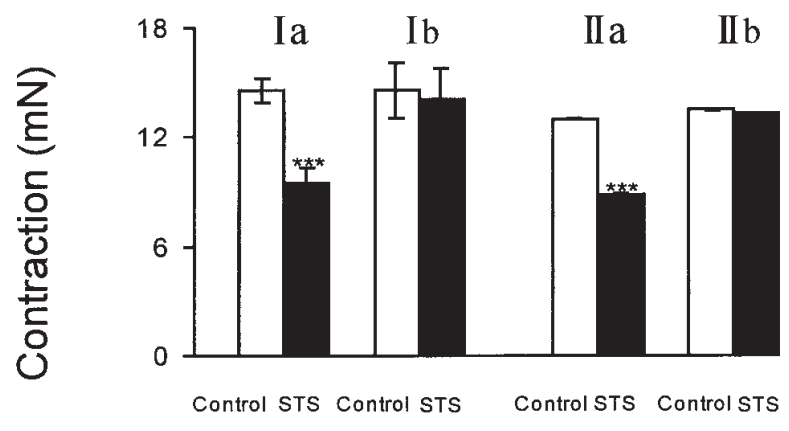

A

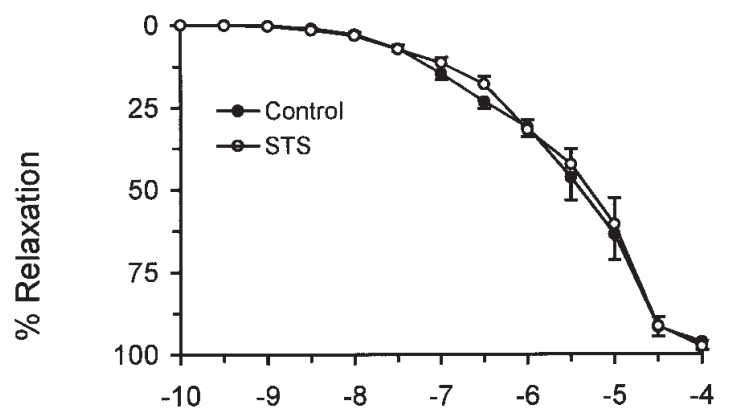

B

\section{Nitroglycerin $\log M$}

Fig 1. A, Mean contraction force $(\mathrm{mN})$ to $\mathrm{U}_{46619}(-8.5 \mathrm{log}$ M). Group I, after incubation with STS or Krebs solution (control) at $4{ }^{\circ} \mathrm{C}$ for 4 hours: group Ia $(n=9)$, washout for 45 minutes; group Ib $(n=7)$, washout for 90 minutes. Group II, after incubation with STS or Krebs solution at $22^{\circ} \mathrm{C}$ for 1 hour: group IIa $(\mathrm{n}=9)$, washout for 45 minutes; group IIb ( $\mathrm{n}$ $=8$ ), washout for 90 minutes. Two artery rings were taken from the same artery and allocated into the paired groups. ${ }^{* * *} P<.001$. B, Endothelium-independent relaxation in microarteries precontracted with $\mathrm{U}_{46619}(-8.5 \log \mathrm{M})$ after incubation with STS or Krebs solution (control) at $22^{\circ} \mathrm{C}$ for 1 hour. There were no differences between the 2 groups.

muscle contractility was impaired by exposure to STS within 45 minutes after exposure but fully recovered after 90 minutes (Fig 1).

Bradykinin-induced relaxation (percentage relaxation of $\mathbf{U}_{46619}$-induced precontraction)

Experimental group I: profound hypothermia $\left(4^{\circ} \mathrm{C}\right)$

Group IA. With the presence of indomethacin (7 $\mu \mathrm{mol} / \mathrm{L})$ and $\mathrm{L}-\mathrm{NNA}(300 \mu \mathrm{mol} / \mathrm{L})$ in control rings incubated in Krebs solution, bradykinin induced a maximal relaxation of $69.0 \% \pm 5.3 \%$ with $\mathrm{EC}_{50}$ of $-7.24 \pm$ $0.09 \log \mathrm{M}$ (Fig 2). Treatment with STS at $4^{\circ} \mathrm{C}$ for 4 hours followed by washout for 45 minutes significantly reduced bradykinin-induced maximal relaxation to $42.7 \% \pm 3.5 \%(\mathrm{n}=9 ; 95 \% \mathrm{CI}, 17.8 \%$ to $34.8 \% ; P=$ .000 ; Fig $2, A$ ) although there was no change on the
Table I. Resting force in coronary microarteries

\begin{tabular}{lcccc}
\hline & \multicolumn{4}{c}{ Resting force $(m N)$} \\
\cline { 2 - 5 } Group & Control & STS & $P$ & $95 \%$ CI \\
\hline $\mathrm{Ia}$ & $5.5 \pm 0.3$ & $5.8 \pm 0.6$ & .6 & -1.41 to 0.86 \\
$\mathrm{Ib}$ & $5.7 \pm 0.6$ & $5.6 \pm 0.7$ & 1.0 & -1.0 to 1.03 \\
$\mathrm{IIa}$ & $5.4 \pm 0.6$ & $5.2 \pm 0.2$ & .7 & -0.97 to 1.3 \\
$\mathrm{IIb}$ & $5.4 \pm 0.4$ & $5.3 \pm 0.4$ & .6 & -0.44 to 0.38 \\
\hline
\end{tabular}

Values are means \pm SE. Group I, after incubation with STS or Krebs solution (control) at $4^{\circ} \mathrm{C}$ for 4 hours; group Ia, washout for 45 minutes; group $\mathrm{Ib}$, washout for 90 minutes $(\mathrm{n}=7$; paired $t$ test). Two artery rings were taken from the same artery and allocated into the paired groups. Group II, after incubation with STS or Krebs solution at $22^{\circ} \mathrm{C}$ for 1 hour; group IIa, washout for 45 minutes; group IIb, washout for 90 minutes after STS or Krebs solution at $22^{\circ} \mathrm{C}$ for 1 hour. Two artery rings were taken from the same artery and allocated into the paired groups.

$\mathrm{EC}_{50}(-7.12 \pm 0.15 \log \mathrm{M} ; \mathrm{n}=9 ; 95 \% \mathrm{CI},-0.22$ to 0.46 $\log \mathrm{M} ; P=.44)$ (Table II).

GROUP IB. In contrast to the group Ia, treatment with STS at $4^{\circ} \mathrm{C}$ for 4 hours followed by washout for 90 minutes did not change the bradykinin-induced relaxation $(55.0 \% \pm 7.2 \%$ vs $58.9 \% \pm 4.6 \% ; \mathrm{n}=7 ; 95 \% \mathrm{CI}$, $-11.0 \%$ to $18.9 \% ; P=.5 ;$ Fig $2, B)$. Similarly, there was no change on the $\mathrm{EC}_{50}(-7.23 \pm 0.08 \log \mathrm{M}$ vs $-7.35 \pm$ $0.06 \log \mathrm{M} ; \mathrm{n}=7 ; 95 \% \mathrm{CI},-0.12$ to $0.38 \log \mathrm{M} ; P=$ .25). These results demonstrate that the bradykinininduced EDHF-mediated relaxation was impaired by exposure to STS for 4 hours at $4{ }^{\circ} \mathrm{C}$ within 45 minutes after exposure but fully recovered after 90 minutes.

Experimental group II: moderate hypothermia $\left(22^{\circ} \mathrm{C}\right)$. The experiments were performed at room temperature $\left(22^{\circ} \mathrm{C}\right)$. The exposure time to either STS or Krebs solution (as the control) was 1 hour. Similar to that mentioned earlier, the washout time was either 45 (group IIa) or 90 (group IIb) minutes.

Group IIA. STS exposure at $22^{\circ} \mathrm{C}$ for 1 hour followed by washout for 45 minutes had a profound effect on bradykinin-induced maximal relaxation $(12.3 \% \pm 1.6 \%$ vs $56.1 \% \pm 4.4 \%$ in the control; $\mathrm{n}=8$; $95 \% \mathrm{CI}, 36.0 \%$ to $51.8 \% ; P=.000 ;$ Fig $3, A$ ) although the $\mathrm{EC}_{50}$ was not significantly changed $(-7.02 \pm 0.17 \log \mathrm{M}$ vs $-7.06 \pm$ $0.13 \log \mathrm{M} ; \mathrm{n}=8 ; 95 \% \mathrm{CI},-0.43$ to $0.52 \log \mathrm{M} ; P=.82$ ) (Table II).

GROUP IIв. The reducing effect of bradykinin-induced relaxation seen in group Ia was eliminated by washout for 90 minutes in group IIb $(60.7 \% \pm 4.3 \%$ vs $62.2 \% \pm$ $5.2 \% ; \mathrm{n}=8 ; 95 \% \mathrm{CI},-6.7 \%$ to $9.8 \% ; P=.7$; Fig $3, B)$ with similar $\mathrm{EC}_{50}(-7.43 \pm 0.08 \log \mathrm{M}$ vs $-7.49 \pm 0.05$ $\log \mathrm{M} ; \mathrm{n}=8 ; 95 \% \mathrm{CI},-0.26$ to $0.13 \log \mathrm{M} ; P=.46$ ).

\section{Discussion}

The present study, for the first time, demonstrates in the coronary microarteries that the indomethacin- 


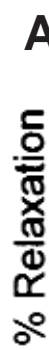

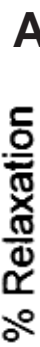

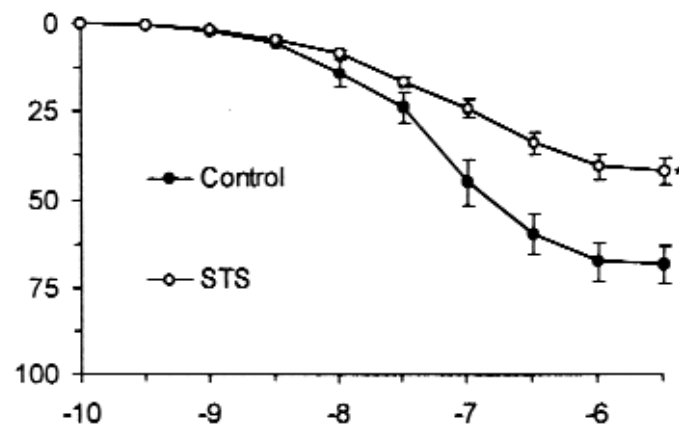

\section{Bradykinin log M}

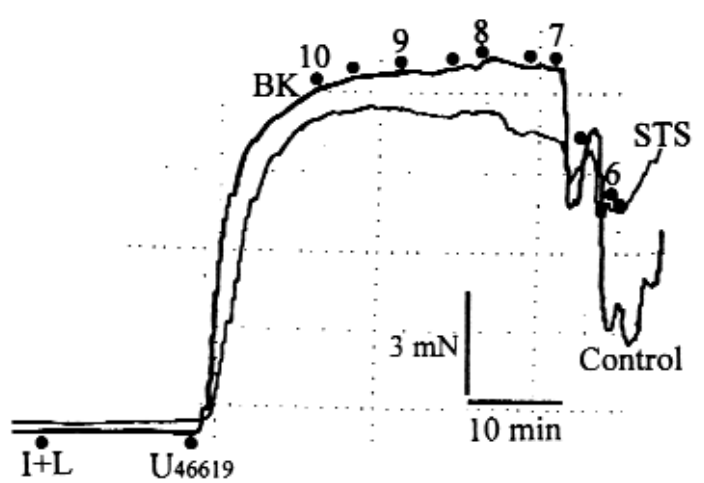

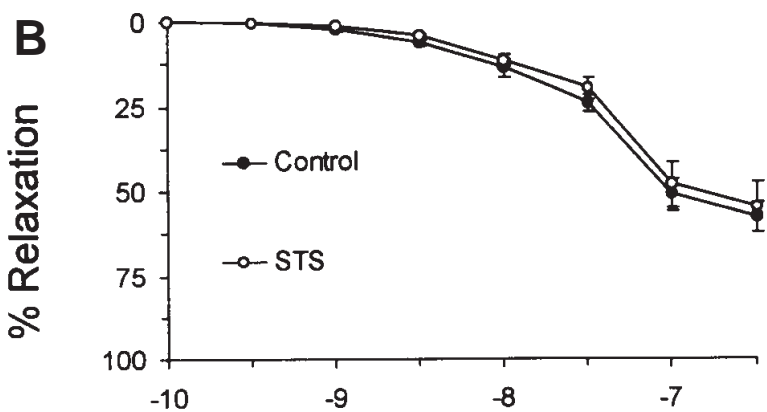

Bradykinin $\log M$

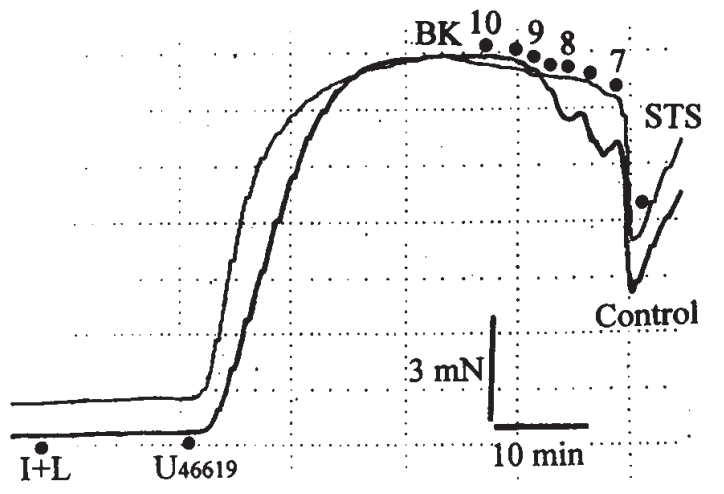

Fig 2. Relaxation of the porcine coronary microarterial rings precontracted with $-8.5 \log M \mathrm{U}_{46619}$ in response to bradykinin $(B K)$ with the presence of $7 \mu \mathrm{mol} / \mathrm{L}$ indomethacin $(I)$ and $300 \mu \mathrm{mol} / \mathrm{L} \mathrm{L-NNA}(L)$ at 45 (A) or 90 (B) minutes of washout after exposure to STS or Krebs solution (control) at $4^{\circ} \mathrm{C}$ for 4 hours. Two artery rings were taken from the same artery and allocated into the paired groups. Top panel (A and B), Mean concentration (log $\mathrm{M}$ )-relaxation (\% of contraction by $\mathrm{U}_{46619}$ ) curves for bradykinin. Vertical error bars are $1 \mathrm{SEM} . \mathbf{A},{ }^{* * *} P=.000$ ( $=9$; paired $t$ test); $\mathbf{B}, P>.05$ at all concentrations $(\mathrm{n}=7)$. Bottom panel (A and $\mathbf{B})$, Digitized traces of original chart recordings from 2 rings taken from the same artery, showing the changes in isometric tension.

Table II. Maximal relaxation and $E C_{50}$ values for bradykinin with the presence of indomethacin $(7 \mu \mathrm{mol} / \mathrm{L})$ and L-NNA $(300 \mu \mathrm{mol} / \mathrm{L})$

\begin{tabular}{|c|c|c|c|c|c|c|c|c|}
\hline \multirow[b]{2}{*}{ Group } & \multicolumn{4}{|c|}{ Maximal relaxation (\%) } & \multicolumn{4}{|c|}{$E C_{50}(\log M)$} \\
\hline & Control & STS & $P$ & $95 \% C I$ & Control & STS & $P$ & $95 \% C I$ \\
\hline $\mathrm{Ia}(\mathrm{n}=9)$ & $69.0 \pm 5.3$ & $42.7 \pm 3.5$ & $<.001$ & $17.8 \sim 34.8$ & $-7.24 \pm 0.09$ & $-7.12 \pm 0.15$ & .44 & $-0.47 \sim 0.21$ \\
\hline $\mathrm{Ib}(\mathrm{n}=7)$ & $58.9 \pm 4.6$ & $55.0 \pm 7.2$ & .5 & $-11.0 \sim 18.9$ & $-7.35 \pm 0.06$ & $-7.23 \pm 0.08$ & .25 & $-0.42 \sim 0.19$ \\
\hline $\mathrm{IIa}(\mathrm{n}=8)$ & $56.1 \pm 4.4$ & $12.3 \pm 1.6$ & $<.001$ & $36.0 \sim 51.8$ & $-7.06 \pm 0.13$ & $-7.02 \pm 0.17$ & .82 & $-0.43 \sim 0.52$ \\
\hline $\mathrm{IIb}(\mathrm{n}=8)$ & $62.2 \pm 5.2$ & $60.7 \pm 4.3$ & .7 & $-6.7 \sim 9.8$ & $-7.49 \pm 0.05$ & $-7.43 \pm 0.08$ & .46 & $-0.13 \sim 0.26$ \\
\hline
\end{tabular}

Values are means \pm SE. Group I, after incubation with STS or Krebs solution (control) at $4^{\circ} \mathrm{C}$ for 4 hours followed by a wash-out for 45 (group Ia) or 90 (group Ib) minutes. Group II, after incubation with STS or Krebs solution at $22^{\circ} \mathrm{C}$ for 1 hour followed by a wash-out for 45 (group IIa) or 90 (group IIb) minutes. Two artery rings cut from the same artery were randomly allocated into the STS and control groups. The $P$ values between paired groups were calculated with a paired $t$ test.

and L-NNA-resistant (EDHF-mediated), endothelialdependent relaxation is reduced after incubation with STS at either moderate or profound hypothermia and that this alteration of the EDHF-mediated relaxation is dependent on the washout time. The effect is seen within 45 minutes after the exposure but eliminated by washout for 90 minutes.
Indomethacin- and L-NNA-resistant (EDHFmediated) endothelial function in the coronary microarteries. Endothelial cells derive 3 major EDRFs. Compared with EDNO and $\mathrm{PGI}_{2}$ that have been well studied, the nature of EDHF has not been finally identified, although most recently the cytochrome P450-mono-oxygenase metabolite of 


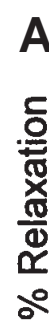

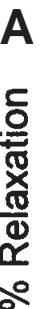

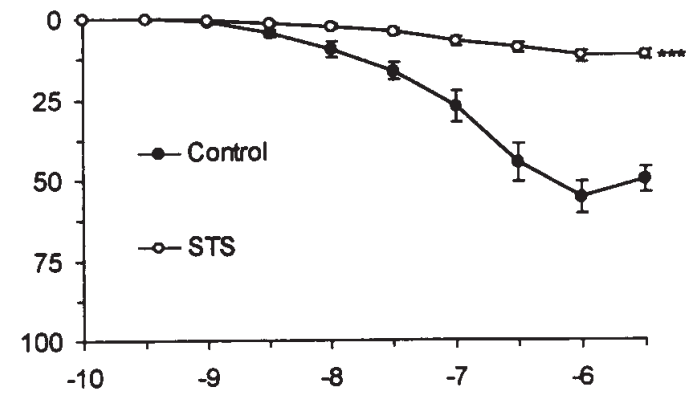

\section{Bradykinin log M}

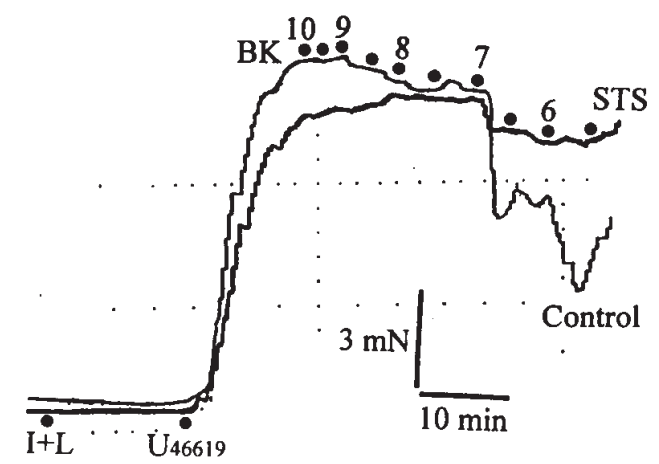

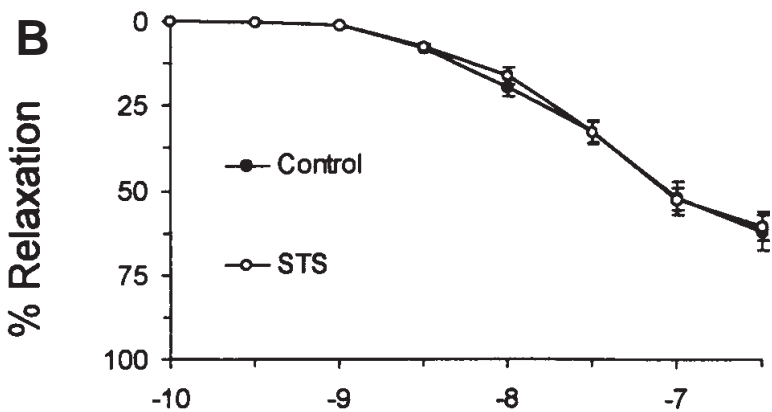

Bradykinin $\log M$

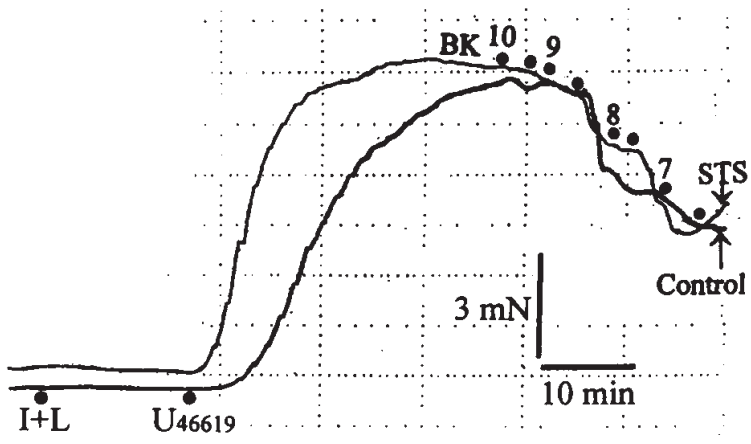

Fig 3. Relaxation of the porcine coronary microarterial rings precontracted with $-8.5 \log \mathrm{M} \mathrm{U}_{46619}$ in response to bradykinin $(B K)$ with the presence of $7 \mu \mathrm{mol} / \mathrm{L}$ indomethacin $(I)$ and $300 \mu \mathrm{mol} / \mathrm{L} \mathrm{L}-\mathrm{NNA}(L)$ at $45(\mathbf{A})$ or 90 (B) minutes of washout after exposure to STS or Krebs solution (control) at $22^{\circ} \mathrm{C}$ for 1 hours. Two artery rings were taken from the same artery and allocated into the paired groups. Top panel (A and B), Mean concentration (log M)- relaxation ( $\%$ of contraction by $\mathrm{U}_{46619}$ ) curves for bradykinin. Vertical error bars are 1 SEM. A, ${ }^{* * *} P=.000$ ( $\mathrm{n}=8$; paired $t$ test); $\mathbf{B}, P>.05$ at all concentrations $(\mathrm{n}=8)$. Bottom panel ( $\mathbf{A}$ and $\mathbf{B})$, Digitized traces of original chart recordings from 2 rings taken from the same artery, showing the changes in isometric tension.

arachidonic acid has been suggested to be EDHF ${ }^{19-21}$ EDHF induces vascular smooth muscle relaxation by hyperpolarization of the smooth muscle cells, which may involve potassium $\left(\mathrm{K}^{+}\right)$channels. ${ }^{7,22-24}$ In contrast, EDNO relaxes blood vessels through the cyclic guanosine monophosphate pathway. However, all of these EDRFs are released in response to the increase of intracellular (cytosolic free) calcium concentration in the endothelial cell. 6,7

Although the exact role of EDHF in regulating vascular tone and in the development of vascular diseases is still unclear, there is evidence that shows that EDNO and EDHF are 2 primary mechanisms of endotheliumdependent relaxation. ${ }^{25,26}$ We have previously reported that EDHF plays a role in large conductance coronary arteries. ${ }^{7,14-16}$ It has been suggested that EDHF plays an even more important role in the regulation of the vascular tone in microcirculation than in the large conductance arteries. ${ }^{8}$ In the present study, all experiments were performed in the presence of the inhibitors of
EDNO and $\mathrm{PGI}_{2}$ (L-NNA and indomethacin) and therefore the bradykinin-induced relaxation is EDHF mediated. We have previously reported that this relaxation is linked with a membrane hyperpolarization in the coronary conductance arteries ${ }^{16}$ and in microarteries. ${ }^{27}$ In our experiments, the EDHF-stimulus bradykinin induced $62.2 \%$ relaxation of the $\mathrm{U}_{46619}$-induced precontraction, which reveals the role of EDHF in the regulation of the tone in the microarteries. Studies have also shown that EDHF may back up or enhance the relaxing action of EDNO, particularly when EDNOmediated relaxation is impaired ${ }^{28}$ as seen in some pathologic status such as hypercholesterolemia, hypertension, and diabetes mellitus. ${ }^{28}$ It may be true that in the coronary microcirculation during ischemia and reperfusion period, when the EDNO mechanism is impaired, ${ }^{29}$ the EDHF-mechanism may play an important role in regulating the coronary circulation.

EDHF-related relaxation after STS exposure and possible mechanism. The effect of STS on the EDHF- 
mediated endothelial function is shown by the reduced relaxation induced by bradykinin after exposure to STS under profound hypothermia for 4 hours (group Ia) or under moderate hypothermia for 1 hour (group IIa), followed by washout for 45 minutes. These results clearly demonstrate that, during the initial reperfusion period, the EDHF-mediated relaxation in the microvessels is altered. We have previously reported that hyperkalemia damages the EDHF-mediated relaxation.,14-16 Because STS is hyperkalemic $\left(20 \mathrm{mmol} / \mathrm{L} \mathrm{K}^{+}\right)$, this alteration is most likely related to the high $\mathrm{K}^{+}$. Hyperkalemia reduces the EDHF-mediated relaxation through the prolonged partial membrane depolarization and affecting K-channels. ${ }^{14-16}$ This is also the likely mechanism in the microvessels.

Effect of washout time on EDHF-related relaxation. We previously observed that, as mentioned, the reduced EDHF-mediated relaxation is related to the prolonged partial depolarization of the smooth muscle membrane potential. ${ }^{14-16}$ Logically, such an effect may be possibly reduced with prolonged washout time. We therefore designed 2 different washout periods to examine the EDHF-mediated relaxation. In this study, we are able to support our hypothesis because, in our experiments, it was demonstrated that with a prolonged washout time (90 minutes) the effect of STS on the EDHF-mediated relaxation was eliminated. However, in cardiac operations, the first 45-minute reperfusion period is probably the most critical time when the heart is just resuscitated from ischemia as the result of total arrest. Coronary dysfunction during this period may predispose the heart to reduced myocardial perfusion that is detrimental to the myocardial function.

Contractility of coronary artery after exposure to STS. Under both profound and moderate hypothermia, after exposure to STS, the contraction to $\mathrm{U}_{46619}$ was reduced (Fig 1). This suggests that the coronary artery is still at a partially plegic status at 45 minutes after exposure to STS. Similar to the EDHF-mediated relaxation, the reduced contraction was fully recovered after 90 minutes. This shows that the reduced contraction after exposure to STS is also time dependent.

Clinical implications. The present study suggests that the EDHF-mediated endothelial function in the coronary microarteries is reduced after incubation with STS for either 4 hours at $4^{\circ} \mathrm{C}$ or 1 hour at $22^{\circ} \mathrm{C}$. This effect is seen within the initial 45 -minute reperfusion period and is eliminated at 90 minutes. Therefore during the initial reperfusion period, the altered EDHFmediated relaxation in microcirculation may cause coronary endothelial dysfunction and have a detrimental effect on the myocardial perfusion.
Moderate hypothermia is commonly used in cardiac operations and 4-hour cold $\left(4^{\circ} \mathrm{C}\right)$ storage with STS is used for the donor heart preservation for transplantation operations. Therefore the present study has strong clinical implications with regard to the coronary dysfunction in the microcirculation in cardiac operations and heart transplantation.

\section{REFERENCES}

1. Demertzis S, Wippermann J, Schaper J, et al. University of Wisconsin versus St Thomas' Hospital solution for human donor heart preservation. Ann Thorac Surg 1993;55:1131-7.

2. Fremes SE, Zhang J, Fruukawa RD, Mickle DAG, Weisel RD. Adenosine pretreatment for prolonged cardiac storage an evaluation with St Thomas' Hospital solution and University of Wisconsin solutions. J Thorac Cardiovasc Surg 1995;110:293301.

3. He G-W, Yang C-Q, Wilson GJ, Rebeyka IM. Tolerance of epicardial coronary endothelium and smooth muscle to hyperkalemia. Ann Thorac Surg 1994;57:682-8.

4. Mankad PS, Chester AH, Yacoub MH. Role of potassium concentration in cardioplegic solutions in mediating endothelial damage. Ann Thorac Surg 1991;51:89-93.

5. Furchgott RF, Zawadzki JV. The obligatory role of endothelial cells in the relaxation of arterial smooth muscle by acetylcholine. Nature 1980;288:373-6.

6. Mombouli J-V, Vanhoutte PM. Endothelium-derived hyperpolarizing factor(s): updating the unknown. Trends Pharmacol Sci 1997;18:252-6.

7. He G-W, Yang C-Q, Graier WF, Yang J-A. Hyperkalemia alters EDHF-mediated hyperpolarization and relaxation in coronary arteries. Am J Physiol 1996;271:H760-7.

8. Garland CJ, Plane F, Kemp BK, Cocks TM. Endothelium-dependent hyperpolarization: a role in the control of vascular tone. Trends Pharmacol Sci 1995;16:23-30.

9. Murphy CO, Pan-Chih, Gott JP, Guyton RA. Coronary microvascular reactivity after ischemic cold storage and reperfusion. Ann Thorac Surg 1997;63:20-7.

10. Follette DM, Buckberg GD, Mulder DG, Fonkalsrud EW. Deleterious effects of crystalloid hyperkalemic cardioplegic solutions on arterial endothelial cells. Surg Forum 1980;31:253-5.

11. Lee J, Drinkwater DC, Laks H, et al. Preservation of endothelium-dependent vasodilation with low-potassium University of Wisconsin solution. J Thorac Cardiovasc Surg 1996;112:103-10.

12. Keller MW, Geddes L, Spotnitz W, Kaul S, Duling BR. Microcirculatory dysfunction following perfusion with hyperkalemic, hypothermic, cardioplegic solutions and blood reperfusion. Circulation 1991;84:2485-94.

13. Sellke FW, Shafique T, Schoen FJ, Weintraub R. Impaired endothelium-dependent coronary microvascular relaxation after cold potassium cardioplegia and reperfusion. J Thorac Cardiovasc Surg 1993;105:52-8.

14. He G-W, Yang C-Q. Impaired endothelium-derived hyperpolarizing factor-mediated relaxation in coronary arteries by cold storage with University of Wisconsin solution. J Thorac Cardiovasc Surg 1998;116:122-30.

15. He G-W. Hyperkalemia exposure impairs EDHF-mediated endothelial function in the human coronary artery. Ann Thorac Surg 1997;63:84-7. 
16. He G-W, Yang C-Q, Yang J-A. Depolarizing cardiac arrest and endothelium-derived hyperpolarizing factor-mediated hyperpolarization and relaxation in coronary arteries: the effect and mechanism. J Thorac Cardiovasc Surg 1997;113:932-41.

17. Mulvany MJ, Halpern W. Contractile properties of small arterial resistance vessels in spontaneously hypertensive and normotensive rats. Circ Res 1977;41:19-26.

18. He G-W, Angus JA, Rosenfeldt FL. Reactivity of the canine isolated internal mammary artery, saphenous vein, and coronary artery to constrictor and dilator substances: relevance to coronary bypass graft surgery. J Cardiovasc Pharmacol 1988;12:1222.

19. Hecker M, Bara AT, Bauersachs J, Busse R. Characterization of endothelium-derived hyperpolarizing factor as a cytochrome P450-derived arachidonic acid metabolite in mammals. J Physiol 1994;481:407-14.

20. Campbell WB, Gebremedhin D, Pratt PF, Harder DR. Identification of epoxyeicosatrienoic acids as endotheliumderived hyperpolarizing factors. Circ Res 1996;78:415-23.

21. Baron A, Bény J-L. Epoxyeicosatrienoic acids activate a highconductance, $\mathrm{Ca}^{2+}$-dependent $\mathrm{K}^{+}$channel on pig coronary artery endothelial cells. J Physiol 1997;504:537-43.

22. Zygmunt PM, Edwards G, Weston AH, Larsson B, Högestätt ED. Involvement of voltage-dependent potassium channels in the EDHF-mediated relaxation of rat hepatic artery. Br J Pharmacol 1997;121:141-9.
23. Petersson J, Zygmunt PM, Högestätt ED. Characterization of the potassium channels involved in EDHF-mediated relaxation in cerebral arteries. Br J Pharmacol 1997;120:1344-50.

24. Ohlmann P, Martinez MC, Schneider F, Stoclet JC, Andriantsitohaina R. Characterization of endothelium-derived relaxing factors released by bradykinin in human resistance arteries. Br J Pharmacol 1997;121:657-64.

25. Cowan CL, Cohen RA. Two mechanisms mediated relaxation by bradykinin of pig coronary artery: NO-dependent and independent responses. Am J Physiol 1991;261:H830-5.

26. Kemp BK, Cocks TM. Evidence that mechanisms dependent and independent of nitric oxide mediate endothelium-dependent relaxation to bradykinin in human small resistance-like coronary arteries. Br J Pharmacol 1997;120:757-62.

27. Ge Z-D, He G-W. EDHF relaxes porcine micro-coronary arteries through activation of multiple $\mathrm{K}^{+}$channels [abstract]. FASEB J 1998;12:A366.

28. Cohen RA, Vanhoutte PM. Endothelium-dependent hyperpolarization: beyond nitric oxide and cyclic GMP. Circulation 1995; 92:3337-49.

29. Pearl JM, Laks H, Drinkwater DC, et al. Loss of endotheliumdependent vasodilation and nitric oxide release after myocardial protection with University of Wisconsin solution. J Thorac Cardiovasc Surg 1994;107:257-64. 